\title{
La incurable tristeza de raza: el indígena en la literatura salvadoreña entre 1880 y $1910^{\prime}$
}

\author{
RiCARDO ROQUE \\ Departamento de Comunicaciones y Cultura, \\ UCA El Salvador
}

Silenciosas, casi adustas, con un reflejo de incurable tristeza de raza cincelada en el rostro impasible, como moldeado por la espátula en la greda de una gárgola de abandonado pilón.

Ambrogi, "Camino de la quebrada"

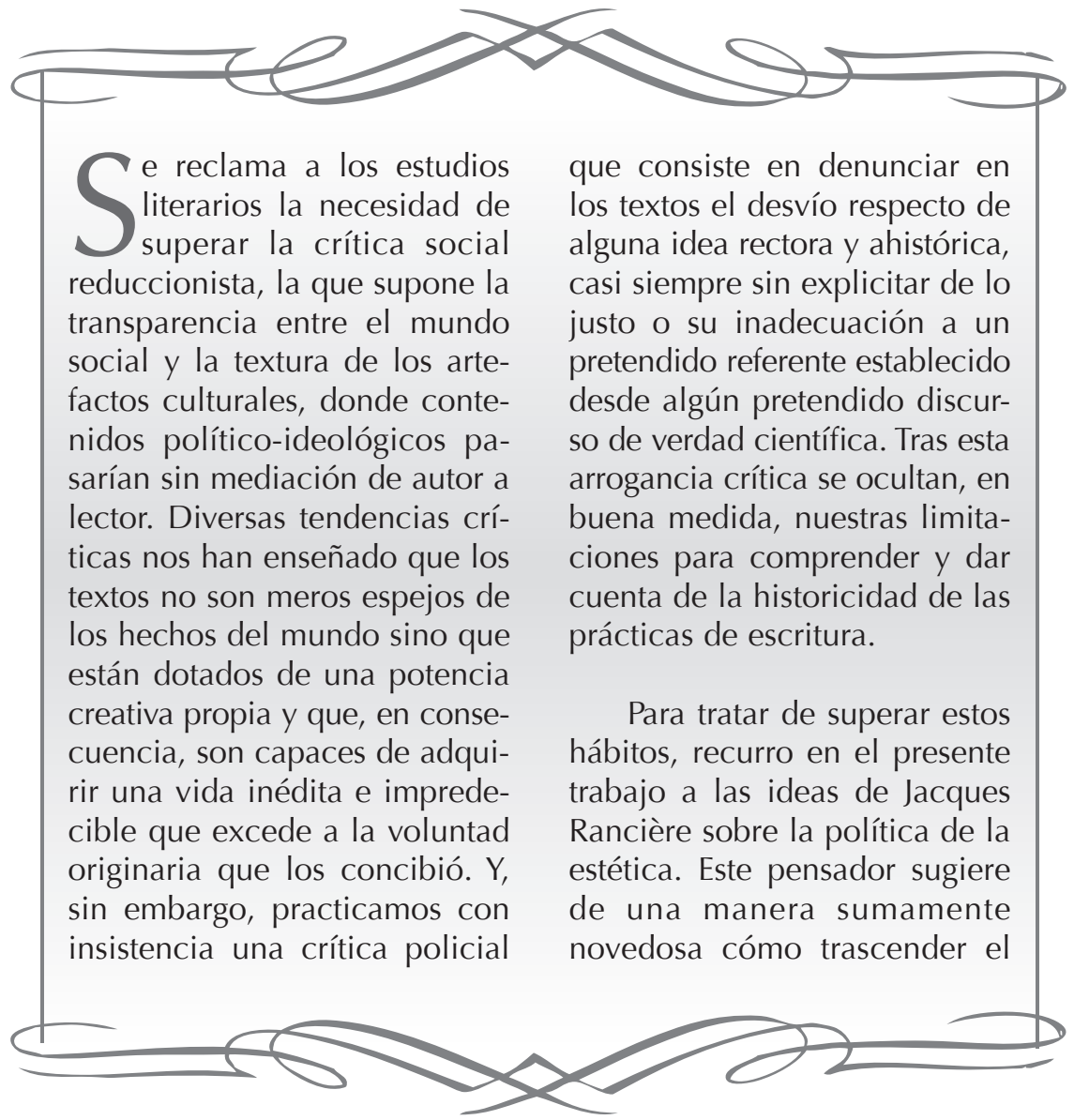


reduccionismo, sin por ello perder el sentido de la literatura como una práctica históricamente concreta. Rancière visualiza una relación original entre la política y la estética precisamente porque parte de una concepción novedosa de la política, a la que no define como el ejercicio del poder $-\mathrm{o}$ la lucha por este-, sino "la configuración de un espacio específico, la circunscripción de una esfera particular de experiencia, de objetos planteados como comunes y que responden a una decisión común, de sujetos capaces de designar a esos objetos y de argumentar sobre ellos" (Rancière, 2005: 18). La política implica pues una dimensión semiótica, o para usar su lenguaje "un reparto de lo sensible" ", una "distribución" y "redistribución de lugares y identidades", una "partición y repartición de espacios y de tiempos, de lo visible y de lo invisible, del ruido y del lenguaje" (18-19).

Es importante aclarar que para Rancière política y estética no son términos ahistóricos sino que se refieren a configuraciones propias de la modernidad. El régimen estético del arte, como una distribución nueva de prácticas culturales que hace posible hablar del "arte" en singular y no de las "artes", supone un nuevo modo de subjetividad política vinculada al surgimiento de la sociedad de masas como entorno natural del lenguaje y a la emergencia de un nuevo sujeto, el "demos". El régimen estético del arte está ligado a la indeterminación de identidades sociales que se generan como resultado de este proceso y a la consecuente desligitimación de la voz como portadora de autoridad. Para Rancière, el régimen estético del arte postula la igualdad de todo asunto y la negación de la necesidad entre una forma y un contenido. Encontramos entonces una comunidad de lectores, pero una comunidad sin legitimidad, formada tan solo por la circulación aleatoria de la palabra escrita. Este régimen se opondría al régimen representativo o poético, que se habría preocupado de postular, a través de la doctrina clásica de las bellas artes -por ejemplo-, un correspondencia estricta y cuidadosa entre géneros discursivos y posiciones sociales. El arte moderno se preocupa así por maneras de ser sensible (aesthesis) y no ya con maneras de imitar (mimesis) ${ }^{3}$.

De lo anterior, se puede establecer que el arte tiene una función política que no consiste ni en la transmisión de contenidos ideológicos ni en su capacidad de representar las estructuras conflictos o identidades, sino que se realiza a través de su especificidad como operación sobre el lenguaje, donde actúa "por el tipo de tiempo y de espacio que establece, por la manera en que divide ese tiempo y puebla el espacio" (Rancière, 2005: 17). Lo propio del arte radicaría así en "practicar una distribución nueva del espacio material y simbólico" (17), es una forma de ocupar un lugar en el que se redistribuyen las relaciones en- 
tre los cuerpos, las imágenes y los tiempos. Lo propio del arte es, en consecuencia, producir disensos, es decir, incertidumbres con relación a las formas ordinarias de la experiencia sensible o consensos.

Este abordaje llevado al examen de la escritura literaria de El Salvador de finales del siglo XIX y de comienzos del siglo XX permite, a mi entender, comprender lo que está en juego en la escritura y dar cuenta de la especificidad de las prácticas estéticas. Los dispositivos literarios no se verían más como meras formas sino como operaciones que demarcan un terreno donde ocurren apuestas políticas. Es así como, en el presente ensayo, trato de dilucidar lo que está en juego en la construcción del indígena como figura central del discurso literario de finales del siglo XIX y comienzos del XX. Recordemos que durante este momento fundacional se recluta a la literatura para configurar un lugar que permita a la sociedad nacional en ciernes acceder al progreso, es decir al espacio-tiempo de la modernidad. En la construcción de esta figura, se efectúan una distribución de tiempos, espacios e identidades que tienen trascendencia en la constitución del espacio político del momento.

Para justificar este abordaje resulta necesario, antes que nada, resolver la cuestión de si se puede hablar de política y estética en el sentido apuntado en una formación social como la salvadoreña, la cual para ese entonces se encuentra escasamente diferenciada. Ello resulta en un Estado débil, una vida urbana precaria y una industria cultural, en el mejor de los casos, incipiente. Creo que podemos responder positivamente a esa interrogante, si acudimos a una concepción de sistema mundo moderno-colonial, donde las diversas formaciones sociales que lo conforman participan, si bien en distintas intensidades, de procesos de modernización global (Quijano, 2005). En este sentido, es posible ver a los circuitos intelectuales latinoamericanos y a prácticas culturales como la literatura como una vanguardia, es decir un espacio de ensayo de formas emergentes de experiencia subjetiva que resultan de determinaciones globales y locales.

Esto no obsta para que sigamos considerando a Centroamérica como un conjunto de sociedades configuradas de manera visible en una dinámica de colonialidad del poder, donde las diferencias entre los grupos que las conforman aparecen fuertemente racializadas (Quijano, 2005). La raza puede verse así como un reparto de lo sensible. El debate en torno a lo indígena se convierte, entonces, en un lugar álgido donde se manifiestan y dirimen demarcaciones fundamentales en la definición del espacio social común. El indígena viene a ser pues un significante que entra al terreno de la literatura con un estatuto 
ambivalente. Por un lado, se parte de postular la inferioridad del indígena como una pieza fundamental en la legitimación del orden social existente. En pocas palabras, en la lógica racista de la colonialidad del saber que anima los debates de la época, lo indígena simboliza la barbarie, el otro de la civilización, de la utopía de progreso que persiguen las élites criollas y ladinas. Sin embargo, lo indígena se convierte también en el medio necesario para reclamar la especificidad cultural nacional, un imperativo de diferencia que, paradójicamente, reclama la lógica homogenizadora de la modernidad.

Esta contradicción se ve operando en el ambiente intelectual salvadoreño de la segunda mitad del siglo XIX. Por un lado, predomina una filosofía positivista que, al suscribir el racialismo científico, condena definitivamente a los pueblos originarios a la barbarie. Se les ofrece, en el mejor de los casos, la vía de la asimilación forzada y la renuncia de su cultura e identidad; en el peor, se pregona de manera más o menos abierta su exterminio o su mantenimiento en un estado de perpetua servidumbre. Por otro lado, ocurre la creciente implantación de la literatura en su régimen estético, donde la indeterminación del lenguaje y sus efectos complejizan el tratamiento de la figura indígena.

Es de notar, sin embargo, que a finales del siglo XIX, la mayor parte de las prácticas de escritura literaria todavía funcionan bajo la lógica de lo que Julio Ramos denomina el modelo de las bellas letras o lo que para Rancière sería un régimen poético o representativo (Ramos, 2003; Rancière, 2000). Esta "literatura" tiene un carácter fuertemente político-didáctico, comprometida con la tarea de dotar al país de una identidad nacional que sirva de cemento para la construcción de un estado nacional moderno. Esta configuración belletrística supone reproducir una preceptiva donde se establece una correspondencia entre las jerarquías de asuntos y de géneros discursivos. El indígena entra aquí bajo dos modalidades. En primer lugar, en ciertas estilizaciones románticas de la épica como elemento que permite dotar a la nación de una tradición, se extraen así réditos a la noble pátina de antigüedad que ofrecen las civilizaciones amerindias, creciente objeto de consideración de la ciencia y la imaginación metropolitana. En segundo lugar, aparece en ciertos géneros menores, notablemente el cuadro de costumbres, donde se denuncia o se ridiculiza la barbarie de los incultos contemporáneos, entre ellos el indígena. Sin embargo, este desfase temporal con la dinámica literaria metropolitana no es tan simple. Para entonces ya circulan en el medio cultural otras modalides de escritura que son asumidas en círculos intelectuales más audaces, notablemente entre los Ilamados modernistas. Aquí se 
comienza a practicar una mirada desestabilizadora de las jerarquías tradicionales entre los temas excelsos y vulgares, así como también empieza a operar una nueva mirada, que se manifiesta atenta a lo cotidiano y lo contemporáneo ${ }^{4}$. Así la realidad indígena no puede pasarse por alto, es un exceso respecto al reparto hegemónico de lo sensible -el discurso civilizadorque no puede dejar de contarse, si bien plantea una presencia perturbadora ante la que se ensayan distintas estrategias de contención.
En lo que sigue de este ensayo, haremos un recuento de cómo distintas figuras de lo indígena en el discurso literario afectan la distribución de lo sensible durante el período que nos ocupa. Para ello, hemos revisado un cuerpo de textos literarios de El Salvador de finales del XIX y comienzos del XX, tanto en libros (Guirnalda salvadoreña, Mayorga, 1977), como en revistas (El fígaro, La quincena) y periódicos (La unión). La elaboración de este trabajo ha supuesto pues el rescate de textos ignorados u olvidados en el debate histórico literario.

\section{Las épicas truncas}

Las contradicciones que conlleva invocar una antigüedad precolombina se ponen en escena en las primeras manifestaciones literarias que inventan una genealogía nacional a través de la composición de épicas indígenistas. Es obvio que esta operación entraña algunos riesgos. Visibilizar a los descendientes de los pueblos originarios, a los excluidos de la modernización, puede significar darle validez a su reclamo histórico como parte afectada por la conquista y la colonia. Sin embargo, este peligro se conjura estableciendo una divisoria temporal drástica, que disloca la conexión histórica de las civilizaciones indígenas con sus descendientes contemporáneos. Esta cesura que separa los tiempos supone una temporalidad, a la manera de Oswald Spengler, fundada en una concepción organi- cista de las civilizaciones con ciclos de nacimiento, apogeo y muerte, con el consiguiente reemplazo por otras más vigorosas, sin que se contemple la posibilidad de diálogo o transculturación (Spengler, 1998). Por ello, veremos que, con insistencia, estas recreaciones épicas del pasado heroico recurren siempre a la premonición de la catástrofe, de la imposibilidad del futuro, del fin ineluctable de un ciclo de civilizaciones enfermas o marcadas por el sino de la desaparición.

Este mecanismo lo vemos operando en la épica indigenista de Joaquín Aragón (1977a, 1977b) recogida en la antología La guirnalda salvadoreña (Mayorga, 1977) en la primera mitad de la década de 1880. Estos poemas estilizan la épica clásica para narrar la saga trágica 
del final de los pobladores originarios como resultado de la conquista española. El indio se convierte así en pretexto para dotar a la comunidad imaginada nacional de una genealogía antigua y prestigiosa, donde se narra, en tono elegíaco, el sino trágico de los pobladores originarios. Sin embargo, esta genealogía se cuida siempre de establecer una conexión directa entre el epos antiguo y la comunidad imaginada que lo exalta. Se establece la barrera infranqueable de su muerte como pueblo, porque lo trágico en estos momentos quiere decir siempre la certera intuición de la muerte del indígena, no tanto en sus individualidades heroicas, sino como estirpe, como raza.

Por dichas razones, la leyenda "Milta o la ruina de Sihautehuacán" de Aragón arranca situando al lector en el vacío de las ruinas que evocan un pasado totalmente agotado, del que no existe siquiera memoria, sino que solo puede ser evocado por la potencia demiúrgica de la imaginación del poeta:

¿En dónde están tus vírgenes lozanas, envidia de las rosas? Tus valientes

campeones ¿dónde están? ¿dónde las ancianas

y severas matronas?; ¿los clementes

caciques qué se hicieron? Sombras vanas

quizá fueron no más, que en sus ardientes

delirios los poetas se forjaron:

¡ni sus gloriosos nombres nos quedaron? (Aragón, 1977a: 323)

El hilo narrativo principal es un romance trágico: el amor suicida entre Milta, la princesa indígena, y don Juan, el guerrero que Pedro de Alvarado manda de avanzada a tierras cuscatlecas. Esta trama podría verse como el esbozo de un posible romance fundacional, a la manera de las ficciones novelescas estudiados por Doris Sommer, que produjera como resultado al mestizo como sujeto del naciente Estado nacional (Sommer, 1991). Sin embargo, aquí no hay síntesis posible. El resultado del amorío entre los dos héroes se frustra con la muerte de ambos y con la subsecuente ruina de Siguatehuacán. Mas, como si esto fuera poco, la destrucción del mundo indígena queda justificada en la leyenda, pues detrás de los personajes nobles, idealizados, como Milta y su padre Axahuat, el cacique de Siguatehuacán, merodea su doble perverso, Tzumalguap, el brujo quien urde la muerte de don Juan e invoca el desastre. Así, el relato cierra con la muerte de Tzumalguap en las manos justicieras de don Diego, el compañero de expedición de don Juan, en la conquista y destrucción de Siguatehuacán: 
Monstruo de iniquidad, el despotismo

Que fue tu progenitor, meció tu cuna

El aire pestilente del abismo:

Ni el tigre ni el chacal, ni fiera alguna

Te podrá igualar; pero ahora mismo,

Aunque hasta hoy te ha minado la fortuna,

Vas a morir cual fiera. Dijo; y luego

A Tzumalguap atravesó Don Diego. (347)

Tzumalguap se convierte en el emblema de la barbarie que debe ser destruida por el conquistador, fuerza que, en la lógica del relato, se convierte en sinónimo del avance inexorable de la modernidad, cruel pero vigorosa, que representa el futuro en una nueva civilización que asume el protagonismo de la historia a la manera del esquema spengleriano.

La antología de Mayorga, recoge otro poema de Aragón donde se ensaya otra estrategia de conexión con el pasado precolombino. El poema "Tecún Umán" exalta la figura heroica del héroe legendario de los quichés, héroe nacional de Guatemala. En este caso, la precisión geográfica es secundaria. Quichés o pipiles, Tecún Umán o Atlacátl sirven al mismo objeto, apuntalar la construcción del sujeto nacional mestizo, a través de una conexión biológica -la cuota indígena en la sangre mestiza- y no cultural o histórica:

¿Y por qué no? ¿acaso no están llenas de la valiente sangre generosa de la raza quiché todas mis venas? ¿Por qué no he de cantar la muerte honrosa del ardido Tecum, que en las arenas de la llanura de Xelahuh gloriosa, defendiendo al Quiché fue derribado por la lanza de Pedro de Alvarado? (347)

Establece pues en este caso, a diferencia de "Milta", una identificación simple entre el indígena del pasado y la nacionalidad moderna. El indígena aparece no como una particularidad étnica en el seno de la sociedad nacional, sino como el emblema de un espíritu de libertad de un sujeto nacional mestizo:

Sufriréis largo tiempo a esos extraños;

pero día vendrá en que valerosos, a la Iberia digais: ya no los daños, 
que causaron vuestros hijos orgullosos, queremos tolerar; ya muchos años

hace que sufrimos silenciosos; mas hoy nuestros derechos pediremos, hombres nacimos; libres viviremos. Y seréis libres. Y tendréis asiento en la asamblea augusta de naciones civilizadas; donde quiera el viento libres tremolarán vuetros pendones.

Y seréis grandes: nadie atrevimiento tendrá para manchar vuestros blasones, que respeto os tendrán, tanto en la guerra, como en la paz, los pueblos de la tierra... (Aragón, 1977b: 352-353)

Y propone la modernidad como el telos en que la nación mestiza puede resarcir la herida de la conquista

Vosotras brisas de la tarde ardientes, que orëasteis la sangre de millares de magnánimos indios inocentes que por su Rey lidiaron y sus lares y el ibero mató: a esos valientes campeones de su patria y sus hogares decidles: que el Quiché ya está vengado, y es pueblo libre, culto y esforzado. (353)

Cualquier reclamo de especificidad histórica del indígena se funde en un sujeto nacional: "libre, culto y esforzado", es decir vaciado de toda diferencia, homogenizado y disciplinado para la modernidad. El indígena como figura de este discurso literario entre épico y trágico sólo tiene la opción de morir para dejar como ejemplo su absoluta entrega a un fin superior, la lealtad a la patria. Esta brecha en el tiempo implica consecuentemente el vaciamiento del espacio indígena presente. Su espacio son las ruinas desiertas del presente. La negativa de concederle al indígena un lugar en el presente de la vida nacional, significa sobre todo el destierro del futuro, del progreso, para consolarse en una bella muerte y quedar recluido en las etéreas y nobles regiones del pasado. Eso explica la importancia del indio como figura en la propuesta cultural modernizante. En esta propuesta, el indígena va a jugar un papel importante, si bien en negativo, para definir el espaciotiempo de la modernización. 
Como hemos visto, esta figuración de lo indígena obedece a un régimen artístico más tradicional $y$, por ende, planteado en términos de una utilidad social expresa: la promoción de un ideario liberal y de la fundación secular de un sentido nacional. Es la literatura de la configuración de las bellas letras, de los polígrafos letrados, que tiende a funcionar bajo un régimen representativo, dominado por la preceptiva y por una correspondencia directa entre temas y géneros discursivos. Este es el que continúa operando en el siglo siguiente en otro tipo de escritura, comprometida de manera más deliberada con el objeto didáctico de exaltar el sacrificio a la patria como valor nacional. Es el caso, por ejemplo, de la reescritura que Juan Antonio Solórzano hace en prosa de "Milta" (1906a; 1906b). Solórzano retoma la mitificación del pasado indígena ya no para establecer un épica nacional, sino un literatura didáctica, un uso instrumental de la escritura de ficción para crear sentido de pertenencia a la comunidad imaginada a un público lector más amplio. En la revista La quincena ${ }^{5}$ encontramos varias entregas de historias de tema indígena escritas por Solórzano, entre ellas una reescritura popular del Popol Vuh, vertiendo sus principales historias en lenguaje sencillo y accesible, tomando como modelo las historia bíblicas (Solórzano, 1907a, 1907b, 1907c, 1907d). Es un intento de hacer un nuevo repertorio de relatos en la religión secularizada que es el nacionalismo. Esto es lo que repite algunas décadas más tarde Miguel Angel Espino en Mitologías de Cuscatlán (Espino, 1996) .

\section{La aparición del indígena contemporáneo}

La voluntad propagandística de promover una pedagogía nacional sigue presente en algunos de los primeros cuentos de temática local escritos en los albores del nuevo siglo. Estos relatos anticipan, ya desde el comienzo, la llamada tendencia vernácula, costumbrista o nacionalista. La quincena acoge con gran entusiasmo en sus páginas estas manifestaciones.

El primer ejemplo que propongo analizar es "Tacho", de Belisario Navarro, obra ganadora de un concurso de cuento promovido por
El diario del Salvador ${ }^{7}$ y luego publicado en La quincena. Belisario Navarro es una figura oscura de quien apenas se tiene noticias. Sabemos que en 1895 habría publicado una reflexión sobre Zola en la revista, también modernista, El figaro ( $\mathrm{Na}$ varro, 1895). Pese a su torpe factura estilística y pobre articulación narrativa, el cuento de Navarro reviste interés por ser quizás el primer texto literario salvadoreño donde se vincula la escena originaria trágica de la conquista, tópico de la figuración de las épicas indigenistas románticas, con la protesta por las tribu- 
laciones del indígena del presente. Encontramos aquí un libreto que se habrá de repetir en la historia de la literatura salvadoreña ${ }^{8}$. Tacho es el campesino -indígena, en este casoque vive en feliz ignorancia en su apartado nicho rural hasta que la violencia de la historia le toca. Sufre una serie de atropellos a manos de ladinos poderosos que culminan en la violación de su esposa. Tacho entonces comprende que debe vengarse, pero también se le revela el sentido de su revancha:

Pero en su alma de esclavo había un germen de amor a la libertad. Y su pensamiento, -no su pensamiento, no- su instinto, le llevó a considerar que él era el dueño de aquella tierra, de que otros gozaban-; que sus antepasados -los libres, no los esclavos- habían sido los únicos señores de ella; y en verdad, era bien amargo que sus sucesores sufrieran en la nueva República todas las cargas, sin que ningún beneficio viniera a compensarlas (Navarro, 1904: 263).

Y en un momento de ensueño, argumento de las épicas truncas: se le aparece nada menos que el

$Y$ en el nebuloso y esfumado horizonte de su alma aletargada, se dibujaron borrosas figuras de un pasado de triunfos, angustia y servidumbre. Vio, como a través de la pálida atmósfera de los ensueños, guerreros coronados por penachos de plumas, disparando flechas sobre sus enemigos: Ios vio, vencedores, clavar sus agudas picas en pechos todavía palpitantes; vio corazones sangrientos, inmolados ante el ara de un Dios vagamente recordado; vio una ciudad magnífica, engrandecida y glorificada por los rayos del Sol, en donde gentes que reconocía iguales a él, habitaban; vio bosques soberbios, maravillosos poemas de vegetación, recorridos por pumas y panteras, que morían a los golpes certeros de gloriosos caciques; y vio que la ley de aquellas gentes, era su ley y sus costumbres y suyas sus alegrías y tristezas; y vio naos de cortantes proas, surcando mares hasta entonces intactos; y vio las blancas velas de las naos, hendiendo aires que antes solo tocaron alas de aves; y vio hombres de otra raza, con cascos relucientes, y petos de acero, y espadas que resplandecían, y con tubos que lanzaban rayos; y vio que esos hombres caían sobre su tierra, montados en monstruos veloces como el viento, 
ensangrentados, rotos, huyendo por las selvas, caídos de su esplendor (ibid.).

La novedad de este pasaje es notoria. Quizá por primera vez en la literatura salvadoreña, se relaciona la gloria del pasado precolombino con un agravio histórico que toca al indígena contemporáneo. Implícitamente se justifica la ira vengativa del protagonista y se abre así la posibilidad de una restitución. Pero ya el texto introduce un detaIle fundamental. Lo que mueve a Tacho no es el "pensamiento", sino el "instinto". Enceguecido por la ira, confundido por la ignorancia, el personaje carga con el lastre de "una gran cruz sangrienta y pesada, negra y enorme" (264), del que no puede librarse y lo embarca en una venganza ciega que lo lleva a la derrota y la muerte. El grito de rabia del indígena oprimido no puede entonces convertirse en justicia, porque no es un acto racional, no es palabra. Desprovisto de voz propia, el indígena queda inhibido de participar por derecho propio en la comunidad nacional. El cuento se convierte en una excusa para hacer propaganda antirreligiosa en el más puro ánimo de liberal exaltado. Y con ello, clama la necesidad de la labor redentora de la razón ilustrada europea, la única capaz de despejar las tinieblas del pasado de odio y atavismos.
De esta forma, se da un nuevo reparto de lo sensible en el cual el indígena presente hace su aparición y conecta la gloria del pasado con su presente miseria, pero es una aparición limitada, donde el indígena no se presenta como un sujeto político capaz, sino como un ser balbuciente, incapaz de hablar. Su voz es un quejido que expresa el dolor y reclama justicia, pero es una redención que no puede emprender por sí mismo, necesita de la intervención de la razón y del Estado moderno que son los únicos que podrán reparar esta injusticia histórica. Cualquier agencia política que pudieran tener los pueblos indígenas es descartada como deseo oscuro de venganza que resulta autodestructivo, pues es la expresión de una barbarie que abarca tanto a oprimidos como a opresores en un literal abrazo mortal en el desenlace del cuento. El espacio-tiempo queda así escindido, entre quienes padecen el atavismo y habitan en el mundo de la necesidad, de la inarticulación bárbara, y quienes habitan el tiempo de la historia que desemboca en el progreso. Esta es una divisoria que se manifiesta en la textura misma de la narración que mantiene la separación nítida, propia del cuadro de costumbres, entre discurso de los personajes y discurso autorial. 
Sabemos que la crónica suple la falta de una novelística conectada con el procesamiento de la cotidianidad moderna en América Latina (Ver Ramos, 2003; Rotker, 2006). Eso es especialmente cierto para un país como El Salvador, donde el carácter incipiente y precario de la industria editorial no permitió el desarrollo de una novelística nacional. La mayor parte de la crónicas salvadoreñas de finales del siglo XIX y comienzos del XX están preocupadas por explorar la vida urbana o, en todo caso, la proximidad y tensión entre el campo y la ciudad que es particularmente crítica en una sociedad de base agraria y de precario desarrollo urbano ${ }^{9}$. La crónica, por otra parte, no es ya la obra de polígrafos letrados que tratan de publicitar un proyecto de nación desde la atalaya del saber, sino el trabajo mucho más modesto en términos políticos pero ambicioso en términos literarios, de escritores que intentan aprovechar estratégicamente el espacio abierto por el periodismo masivo de información.

Tal es el caso de la crónica "Los indios de Izalco" de Román Mayor- ga Rivas publicada en la revista La quincena (Mayorga, 1906) ${ }^{10}$. Este trabajo reviste un especial valor y un índice de cómo la literatura está asumiendo la complejidad étnica de El Salvador. La crónica de Mayorga Rivas, consecuente con el cometido de la crónica de explorar la cotidianidad, tiene un carácter etnográfico y se dedica a describir con cierto detalle algunos aspectos de las costumbres de los habitantes indígenas de Izalco. Desde las palabras de apertura - "Lejana, muy lejana"- la crónica establece una frontera tajante entre la población indígena y la población ladina que habitan esa ciudad de occidente. Recordemos que Izalco es una ciudad de El Salvador donde estos dos grupos han experimentado una compleja y tensa coexistencia desde tiempos coloniales. Esto se evidencia en su planta urbana, con sus dos barrios principales, Asunción y Dolores, que son colindantes y albergan respectivamente a indígenas y ladinos. Para Mayorga, ingresar al Barrio de la Asunción es así un viaje en el tiempo y la imaginación:

En Izalco hay descendientes de aquellos indios dueños de este país que vinieron a conquistar los castellanos. Entre ellos, espontánea como la planta que en la selva nace, la tradicional costumbre se manifiesta en determinadas ocasiones y surge ante nuestra imaginación la antigua época de Cuscatlán, con toda su misteriosa poesía paradisíaca y leyendas de amores, guerras, infortunios, riquezas, sacrificios y victorias (56). 
Es un viaje que se ofrece a la mirada del contemplador ladino, nos remonta nuevamente al pasado glorioso de la comunidad carismática perdida. Pero que pertenece al orden de la naturaleza y a un tiempo inevitablemente pasado: "una raza que pasó por los campos de la vida y de la historia dejando en ellos resplandores de su alma y regueros de su sangre" (56).

Los indígenas contemporáneos existen pero sólo como vestigios que se ofrecen a excitar la imaginación del lector ladino contemporáneo. Y sus expresiones, lejos de ser la afirmación de una identidad propia o la postulación de un reclamo histórico de igualdad, son vagos quejidos, lamentos inarticulados. La flauta que se describe como instrumento "selvático" (56), las mujeres que danzan con "rusticidad sugestiva" (57), el ritmo del teponahuaxte "que suena con quejidos roncos, profundos e inacabados" (56), todos son una suerte de signos que hablan de un estado de fusión con los elementos de la naturaleza primigenia, dejada atrás por la modernidad. De allí que la crónica se cierre con la imagen del volcán "Izalco [que] retumba poderoso y mancha de humo el cielo azul que sirve de palio a la comarca" (57). El escenario humano se transfigura en una suerte de escenario telúrico, donde el volcán y el cielo son parte de una escenografía natural.

Hay en este texto una nueva política de la literatura, es decir una distribución de tiempos, espacios e identidades, que juega un doble papel. Por un lado, de visibilización del indígena contemporáneo como habitante próximo de la geografía nacional. Por otro lado, sin embargo, opera otra operación en sentido inverso que termina por alejarlo de manera más decisiva al situarlo en otro tiempo habitado por otra humanidad, salvaje, precultural, "espontánea como la planta que en la selva nace" (56). El indígena es nuestro vecino, nuestro prójimo, pero no habita nuestro tiempo, no habla nuestro lenguaje. Su mundo pertenece a otro orden de cosas. Es, en el mejor de los casos, el lamento por la pérdida irrecuperable de la armonía de lo humano y lo natural, de una cierta comunidad carismática perdida, que no sin alguna dosis de melancolía resalta la caída de esa gracia primigenia que padecen el cronista y sus pretendidos lectores.

\section{El cuerpo indígena como emblema estético}

Contemporáneo a los textos de Navarro y Mayorga Rivas son dos prosas poéticas de Arturo Ambrogi, reunidas en El libro del trópico, una compilación que reúne una serie heterogénea de crónicas, poemas en prosa y narraciones que se publica por primera vez en formato de libro en $1907^{11}$. Los poemas en prosa de esta compilación son una 
especie de depuración de la lógica impresionista de la crónica que este autor había cultivado desde sus primeros trabajos literarios. Ambrogi culmina aquí la aventura literaria de una poética de los objetos o, en sus palabras, "una filosofía del hecho menudo"12. El libro del trópico se mueve del ambiente urbano que había sido el foco atención de sus primeras obras, y se dedica a reencantar la prosa de la vida campestre para elevarla, gracias al instrumento de su elaborado estilo, al estatuto de obra de arte.

La primera de estas prosas, "La pesca bajo el sol" (Ambrogi, 1907: 33-36) ${ }^{13}$, detiene totalmente la narración y consiste de la descripción detallada y en estilo virtuoso del cuadro de un pescador en medio de su faena:

El cuerpo moreno, fuerte y toscamente moldeado en el barro de la tierra, repujado luego por el aire libre de la montaña y robustecido por las pujantes faenas. Las espaldas, anchas y nudosas, en las que los omoplatos [sic] resaltan en vigoroso relieve, están requemadas por el sol: tienen ese color obscuro y patinoso del cacao [...] el cuerpo desnudo y atezado, evoca la imagen de una raza desaparecida, sana y libre, vaciada en el barro de la tierra, fortalecida por el trabajo rudo, llena de músculos, vigorosa y terrible, ante la cual medita y siente nostalgias primitivas, regresiones selváticas, nuestra vanidosa enclenquitud barnizada de una seudo-civilización necia y pedante (33-34)

Encontramos, a primera vista, una reiteración de las operaciones antes consignadas. La presentación del indígena como una corporalidad fundida con el entorno natural que remite a una época remota de armonía con el cosmos y el atavismo que se despierta en el contemplador moderno. Sin embargo, en este caso, la valoración cambia. Lo que era un eco melancólico aquí se manifiesta como una protesta por el mal de los tiempos. El espectador es quien ahora se sitúa en una civilización enfermiza, la moderna, enervada por el tedio, por la prosa de la vida, y desde allí idealiza la fortaleza y virilidad primigenia del contemplado, su pertenencia a un mundo cerrado armónico, a una comunidad estética. Por eso, la pesca que realiza el espectador no obedece a una voluntad individual:

Aquel acto es maquinal. Así viene de sus antepasados. Así lo vio hacer al abuelo, cuando le llevaba a la pesca para que cargase con la cebadera; así lo vio hacer a su padre, 
que a pescozones le enseñó la maniobra; así lo hace él ahora, y así lo hará su hijo mañana: tirar la misma atarraya, que pasa de padres a hijos cuidada con solicitudes filiales, esperar, y luego retirarla. $Y$ así siempre, hasta que nueva mano la recoja de la vieja (34).

Es el tiempo de la repetición que antecede la historia y que soprepasa al individuo. La estructura anafórica del pasaje citado lo estiliza magistralmente. De esta manera, el pescador indígena se sitúa en otro tiempo, aun cuando se haga presente ante la mirada del contemplador moderno. Hasta aquí tendríamos una variación de grado mínimo con respecto al texto de Mayorga Rivas. Pero en la textura de esta prosa, sucede algo desconcertante. A la par de la operación de separación, opera otra en sentido contrario. En la medida que prolifera la lógica miniaturista de la descripción, el pescador y los objetos del mundo natural con los que está fundido terminan compartiendo el espacio de la página con otros objetos lujosos, delicados, propios de la cotidianidad estetizada de la sociedad cosmopolita:

El paisaje que forma ambiente a la escena, es todo de luz. Todo irradia, todo reluce. Un jirón de cielo del mediodía se refleja en el agua tranquila, profundizándola, Ilenándola de ensueño y de quimera; el agua azul y brillante de las Mil y Una Noches: el agua de oro, compañera del pájaro que habla y del árbol que canta; el agua azul y brillante de las fuentes de los poetas... Y en la misma sombra, junto a los sauces y los chilamates, las redes intrincadas de algas se extienden a flor de agua como vaporosas madrileñas de encajes de un purísimo malaquita, mientras que entre los berros tupidos, y la espuma de sapo, las filudas piedras, cubiertas de limo, parecen cabezas de ahogados que la corriente no ha podido arrastrar (36).

En la luz y en la sombra todo se funde. Los chilamates y la espuma de sapo se transubstancian con la malaquita, los encajes madrileños y las Mil y una noches se convierten en una suerte de poesía universal que redime el prosaísmo de los tiempos modernos. Esta operación se manifiesta en la textura de la prosa de Ambrogi, la cual subvierte la divisoria largamente instituida por los cuadros de costumbres, entre un lenguaje rústico de los parlamentos de los personajes vulgares y el estilo elevado de la voz autorial.

Estas operaciones las encontramos también en otra prosa poética, 
"Camino de la quebrada" (Ambrogi, 1907: 57-60) ${ }^{14}$. De un estilo preciosista, de logrados efectos de aliteraciones y paralelismos, nos describe la impresión de un grupo de jóvenes indígenas campesinas en su diario viaje al río para proveerse de agua. Aquí se eleva al estatuto de objeto de contemplación estética el cuerpo de las mujeres indígenas, en una ambivalente oscilación entre la delicada estilización y el elogio de la rusticidad:

Silenciosas, casi adustas, con un reflejo de incurable tristeza de raza cincelada en el rostro impasible, como moldeado por la espátula en la greda de una gárgola de abandonado pilón. No cantan, como las muchachas en los versos crepusculares de los poetas hipocondriacos al volver de la fuente. No cantan caminando, paso a paso, ni se apresuran porque alguien, tal vez, les espere a la orilla de la quebrada, cerca de las claras vertientes. Van; llegan; toman, precisas, el agua; y lleno el cántaro de barro, vuelven al rancho, al mismo paso reposado, con la misma calmosidad, y el mismo reflejo de la incurable tristeza de raza cincelado en el rostro (del color del barro del cántaro y de la tierra asoleada.) (57).

Estos cuerpos rompen los tópicos de la feminidad bucólica clásica, y le ofrecen al contemplador una nueva musa, pero también una música, una nueva textura de los objetos que debe ser leída estéticamente, es decir en sus propios términos, y no en base a una preceptiva clásica. Paralelo a esto, aflora nuevamente el tópico que asocia lo indígena con las regiones de lo misterioso, de lo inefable. De lo que no se puede verbalizar: "una profunda melancolía que ningún poeta ha podido tan siquiera expresar" (60). Es una melancolía que habla nuevamente de una fisura dentro del contemplador, de la parte atávica, indígena que duerme dentro de él, es "una incurable tristeza de raza" que afecta al indígena "indolente", "derrotado", pero también activa algo dentro del prosista y la comunidad de lectores que intenta fundar con su escritura, cuando afirma que "nuestra levadura indígena fermenta; y al oírla, nos ponemos tristes; y nuestra garganta se anuda, y en nuestros ojos punzan lágrimas por quién sabe qué dolor pasado..." (60). Esta melancolía, esta parte atávica es de donde surge la nueva poesía, la que permite redimir la prosa de la vida en una especie de poesía universal de los objetos que hace una operación indiscriminada de nivelación por intermedio del estilo.

En resumen, en la escritura literaria de Ambrogi podemos detectar 
un doble movimiento. Por un lado, a un nivel más explícitamente ideológico, encontramos una reiteración de los tópicos de asimilación de lo indígena a lo telúrico y de destierro del presente. Por el otro lado, sin embargo, se despliega una lógica que emana de la radicalidad de la voluntad de estilo de Ambrogi, que pone en entredicho esas demarcaciones y encarna así una cierta revancha del objeto que anula las ilusiones de omnipotencia del sujeto literario y lo obligan a fundirse en una nueva música esencial del mundo. Lo indígena ha dejado de ser el pasado, para pasar a ser parte de un futuro apenas vislumbrado.

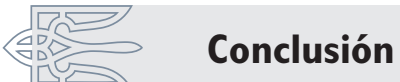

La lógica del esterotipo racial, según nos lo ha mostrado Bhabha, es esencialmente ambivalente. Puede oscilar entre la demonización y la idealización. Pero el otro nunca escapa de ser la proyección ansiosa de un "mismo" que busca definirse por su intermedio (Bhabha, 2004). Así, Jeffery Gould y Aldo Lauria-Santiago muestran en su investigación sobre las masacres de 1932, cómo la racionalización oficial pasa de un retrato del indígena como bárbaro o como enfermedad a un lamento sobre la inocencia perdida del buen salvaje por la mano siniestra del comunismo (Gould y Lauria-Santiago, 2008). Esto no es una mera adaptación instrumental y oportunista del discurso dominante ante las circunstancias cambiantes de los hechos. No son dos visiones sobre el indígena, una negativa y una compasiva, son dos caras de la misma lógica de "encubrimiento del otro" (Dussel, 1994), por medio de la cual se siguen reproduciendo los estereotipos racistas, más o menos violentos, con los que se excluye al indígena del proyecto de las sociedad nacionales modernas.
Ahora bien, la cuestión que nos ocupa es decidir si la literatura, por su fatalidad de institución moderna, está predestinada a reproducir, sin escape, esta lógica de encubrimiento, esta violencia originaria de nuestra condición colonial. Esta es la acusación que se eleva con frecuencia constante desde los estudios poscoloniales.

Desde esta última perspectiva, la incurable tristeza del indio sería la melancolía del sujeto nacional mestizo que debe construirse a partir de una posición que acepta las premisas racistas del eurocentrismo y que se sabe condenado a una insalvable posición subalterna. Así, la conmiseración del indígena y de su destino trágico es la ansiedad del ladino frente al peligro de que los "atavismos de raza" lo inhabiliten para el progreso. Entonces añora un falso paraíso perdido. La invocación del próximo fin del indígena delata así su deseo de que el destierro del indígena del presente, bien sea por la vía de la aculturación o por la del exterminio, conjure de una vez por 
todas la carga de la diferencia racial y le permita asumir la posición eurocéntrica de privilegio con pleno derecho.

Sin embargo, esto solo cuenta una parte de la historia. No debemos olvidar, sin embargo, que la literatura -como la escritura propia del régimen estético del arte- idea espacios donde estas divisiones nítidas se desestabilizan. Y es así como la expulsión del indígena del futuro acaba por revertirse sobre el mismo intelectual que articula el discurso literario. La precariedad de su ubicación periférica en el sistema mundo-colonial le ofrece una insuperable incertidumbre respecto a la promesa de redención del progreso y abre la puerta a disensos que permiten la exploración de nuevas zonas de experiencia que obligan a replantearse las configuraciones de tiempo, espacio e identidad que propone la doxa civilizadora. Será, entonces, el indígena "estetizado" la ficción que permitirá que el pueblo de las luchas democráticas del siglo $\mathrm{XX}$ se encarne.

\section{Obras citadas}

- Ambrogi, Arturo (1907). El libro del trópico (1a. edición). San Salvador: Samuel C. Dawson, editor.

- Aragón, Joaquín (1977a). "Milta, o la ruina de Siguatehuacán". Román Mayorga Rivas (compilador), Guirnalda salvadoreña (Tomo III) (1886), San Salvador, Dirección de Publicaciones del Ministerio de Educación, 1977: 323-347.

(1977b). "Tecún Umán". Román Mayorga Rivas (compilador), Guirnalda salvadoreña (Tomo III) (1886), San Salvador, Dirección de Publicaciones del Ministerio de Educación, 1977: 347-353.

- Bhabha, Homi (2004). "The other question: stereotype, descrimination and the discourse of colonialism". The location of culture: 66-84. Londres y Nueva York, Routledge.

- Dussel, Enrique (1994). 1492. El encubrimiento del Otro. Hacia el origen del "mito de la Modernidad". Conferencias de Frankfurt, Octubre 1991. La Paz, Plural Editores, 1994

- Espino, Miguel Angel (1996). "Mitología de Cuscatlán". Mitología de Cuscatlán/Como cantan allá: 9: 52. San Salvador: CONCULTURA.

- Gould, Jeffrey y Aldo A. Lauria-Santiago (2008). To Rise in Darkness: Revolution, Repression, and Memory in El Salvador, 1920-1932. Durham, Duke University Press, 2008.

- Mayorga Rivas, Román (1906). "Los indios de Izalco". La quincena (San Salvador), año IV, No. 74, 15 de abril de 1906: 56-57. 
1977). Guirnalda salvadoreña (3 volúmenes) (18811886). San Salvador: Dirección de Publicaciones.

- Navarro, Belisario (1895). "Realismo e idealismo (Artículo primero). Zola y Lamartine". El fígaro. Tomo II, No. 22, 22 de septiembre de 1895: 172-173.

(1904). "Tacho". La quincena (San Salvador), Año II., Tomo III, N. 32, 15 julio 1904: 262-264.

- Quijano, Aníbal. (2005). "Colonialidad del poder, eurocentrismo y América Latina". En Lander, Edgardo (ed.). La colonialidad del saber: eurocentrismo y ciencias sociales: 201-246. Buenos Aires: CLACSO.

- Ramos, Julio (2003). Desencuentros de la modernidad en América Latina: literatura y política en el siglo XIX. Santiago de Chile y San Juan de Puerto Rico: Editorial Cuatro Propio/Ediciones Callejón.

- Rancière, Jacques. (2000). Le partage du sensible, esthétique et politique. París: La fabrique éditions, 2000.

(2005). Sobre políticas estéticas Barcelona: Musei d'Art Contemporani de Barcelona, Servei de Publications de la Universitat Autonoma de Barcelona, 2005.

- Roque Baldovinos, Ricardo (2006). "Poéticas del despojo: mestizaje y memoria en la invención de la nación", en Cultura (Revista del Consejo Nacional para la Cultura y el Arte), No. 94, septiembre-diciembre 2006: 11-19.

(2009). "Para un filosofía del hecho menudo. Ambrogi y la crónica modernista", Centroamericana, 15, Cattedra di Lingua e Letterature Ispanoamericane, Università Cattolica del Sacro Cuore, Milán, febrero 2009: 57-86.

- Rotker, Susana (2006). La invención de la cronica, México: Fondo de Cultura Económica.

- Ruby, Christian (2009). L'interruption. Jacques Rancière et la politique. París: La fabrique éditions.

- Solórzano, Juan Antonio (1906a). "Entre el amor y el deber. Últimos días de Ciguatehuacán. (siglo XVI). Leyenda centroamericana" [Primera entrega]. La quincena (San Salvador), Año IV, Tomo VIII, No. 86, 1 de noviembre de 1906: 62-63.

(1906b). "Entre el amor y el deber. Ultimos días de Ciguatehuacán (siglo XVI). Leyenda centroamericana (conclusión)". La 


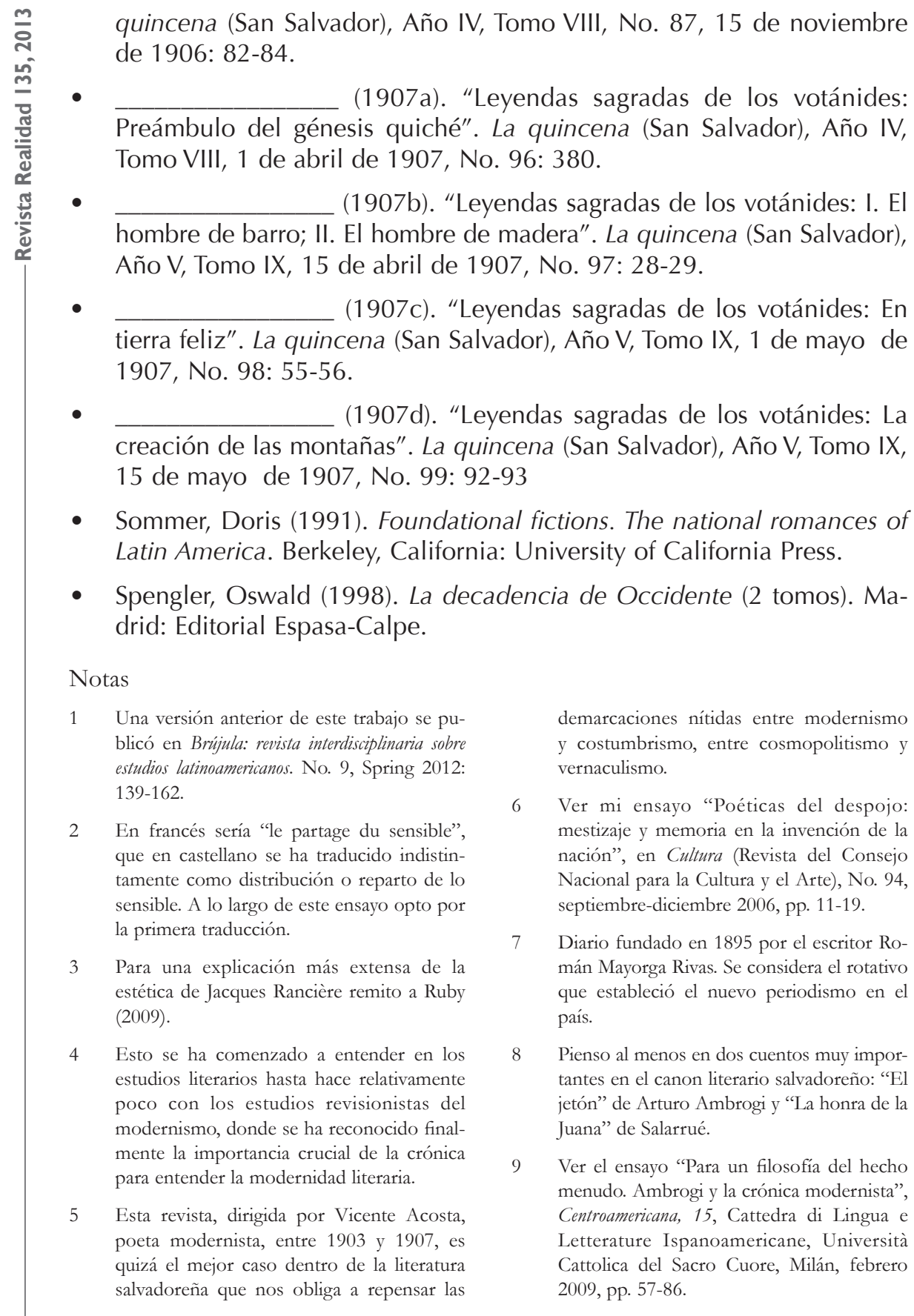

quincena (San Salvador), Año IV, Tomo VIII, No. 87, 15 de noviembre

(1907a). "Leyendas sagradas de los votánides: Preámbulo del génesis quiché". La quincena (San Salvador), Año IV, Tomo VIII, 1 de abril de 1907, No. 96: 380.

(1907b). "Leyendas sagradas de los votánides: I. El hombre de barro; II. El hombre de madera". La quincena (San Salvador), Año V, Tomo IX, 15 de abril de 1907, No. 97: 28-29.

tierra feliz". La quincena (San Salvador), Año V, Tomo IX, 1 de mayo de 1907, No. 98: 55-56.

creación de las montañas". La quincena (San Salvador), Año V, Tomo IX, 15 de mayo de 1907, No. 99: 92-93

Sommer, Doris (1991). Foundational fictions. The national romances of drid: Editorial Espasa-Calpe.

demarcaciones nítidas entre modernismo y costumbrismo, entre cosmopolitismo y vernaculismo.

estudios latinoamericanos. No. 9, Spring 2012: mestizaje y memoria en la invención de la nación", en Cultura (Revista del Consejo Nacional para la Cultura y el Arte), No. 94, septiembre-diciembre 2006, pp. 11-19. sensible. A lo largo de este ensayo opto por estética de Jacques Rancière remito a Ruby estudios literarios hasta hace relativamente poco con los estudios revisionistas de modernismo, donde se ha reconocido finalmente la importancia crucial de la crónica quizá el mejor caso dentro de la literatura salvadoreña que nos obliga a repensar las 
10 Román Mayorga Rivas es un escritor de origen nicaragüense cuya contribución a la vida literaria salvadoreña es fundamental. Como vimos más arriba es el editor de $L a$ guirnalda salvadoreña, antología publicada en la década de 1880 que intenta hacer una recolección de los poetas más destacados del país. Hacia 1895, funda El diario del Salvador. Mayorga Rivas, que por lo visto no quería desvincularse del todo del mundo literario, tiene numerosas contribuciones en la revista La quincena, como la presente crónica.

11 Ambrogi elabora dos versiones más de este libro en 1915 y 1918, cada una de las cuales supone un proceso intenso de reescritura. $\mathrm{La}$ edición más conocida es la definitiva, la de 1918. Sin embargo, he preferido examinar la primera porque en ella es mucho más patente la proximidad y tensión del autor con el modernismo. Las primeras versiones de estas prosas fueron, por cierto, publicadas por primera vez en La quincena.

12 Ver nota 9

13 La primera versión de esta prosa es la primer adelanto de El libro del trópico publicado en La quincena (Año I, tomo II, No. 14, 15 octubre de 1903: 49-51). Aparece con el encabezado "Páginas del trópico" y con la siguiente dedicatoria: "A Julia B. de Soto Hall, en Guatemala”. Citamos la versión que aparece en la edición de 1907.

14 La primera versión se publica en La quincena (Año III, tomo V, No. 56, 15 julio de 1905: 246-247), bajo el encabezado "El libro del trópico". Posteriormente es reunida la primera edición de El libro del trópico. 